Materials Science \& Engineering A 710 (2018) 214-226

Contents lists available at ScienceDirect

Materials Science \& Engineering A

journal homepage: www.elsevier.com/locate/msea

High temperature creep properties of a linear friction welded newly developed wrought Ni-based superalloy

F. Masoumi ${ }^{\mathrm{a}, *}$, L. Thébaud ${ }^{\mathrm{b}, \mathrm{c}}$, D. Shahriari ${ }^{\mathrm{a}}$, M. Jahazi ${ }^{\mathrm{a}, *}$, J. Cormier ${ }^{\mathrm{b}}$, A. Devaux ${ }^{\mathrm{c}}$, B.C.D. Flipo ${ }^{\mathrm{d}}$

a Department of Mechanical Engineering, École de Technologie Supérieure (ÉTS), Montreal, QC, Canada H3C 1 K3

' Institute Pprime, UPR CNRS 3346, Physics and Mechanics of Materials Department, ISAE, ENSMA, BP 40109, Futuroscope, Chasseneuil Cedex 86961, France

${ }^{c}$ Aubert \& Duval, Site des Ancizes, BP1, 63770 Les Ancizes Cedex, France

d TWI Ltd, Granta Park, Great Abington, Cambridge CB21 6AL, UK

Authors' accepted manuscript

Article published in Materials Science and Engineering: A, vol. 710 (2018)

https://doi.org/10.1016/j.msea.2017.10.091

(C) 2018. Made available under the CC-BY-NC-ND 4.0 license

http://creativecommons.org/licenses/by-nc-nd/4.0/ 


\title{
High Temperature Creep Properties of a Linear Friction Welded Newly Developed Wrought Ni-Based Superalloy
}

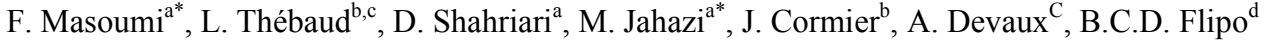 \\ ${ }^{a}$ Department of Mechanical Engineering, École de Technologie Supérieure (ÉTS), \\ H3C 1K3, Montreal, QC, Canada \\ ${ }^{\mathrm{b}}$ Institute Pprime, UPR CNRS 3346, Physics and Mechanics of Materials Department, ISAE- ENSMA, \\ BP 40109, Futuroscope- Chasseneuil Cedex 86961, France \\ ${ }^{c}$ Aubert \& Duval, Site des Ancizes, BP1, 63770 Les Ancizes Cedex, France \\ d TWI Ltd, Granta Park, Great Abington, Cambridge CB21 6AL, UK \\ *Fatemeh.Masoumi.1@ens.etsmtl.ca \\ *Mohammad.Jahazi@etsmtl.ca
}

\begin{abstract}
$\mathrm{AD} 730^{\mathrm{TM}} \mathrm{Ni}$-based superalloy specimens in solution-treated conditions were linear friction welded. Then, post-weld heat treatment (PWHT), consisting of $\gamma^{\prime}$ sub-solvus solution treatments followed by aging, was conducted on the linear friction welded samples. High temperature creep tests were performed on the as-welded and PWHTed joints at two different temperatures: $700^{\circ} \mathrm{C}$ under 600 and $750 \mathrm{MPa}$ stress levels, and $850^{\circ} \mathrm{C}$ under 100 and $200 \mathrm{MPa}$ stresses. The creep resistance of the PWHTed joints was higher than that of the as-welded samples. The PWHTed joints exhibited better ductility than that of the base material at $850^{\circ} \mathrm{C}$, while they showed slightly lower creep life at $700^{\circ} \mathrm{C}$ in comparison to the base metal. Microstructure examination showed that cracks initiated at the interface of oxidized particles at $700^{\circ} \mathrm{C}$. The decrease in creep resistance of the $\mathrm{AD} 730^{\mathrm{TM}} \mathrm{Ni}$-based superalloy at $850^{\circ} \mathrm{C}$ was related to a combination of the formation of precipitate-free zones (PFZ) in the vicinity of the grain boundaries (GBs) and microcracking assisted by oxidation. The Larson-Miller Parameter (LMP) was used to correlate the creep strength, temperature and time to failure for the as-welded and PWHTed samples. LMP values varied between $21.5 \times 10^{3}$ and $24.5 \times 10^{3}$. It was found that in the investigated temperature range, the PWHTed AD $730^{\mathrm{TM}}$ has similar creep characteristics as Udimet ${ }^{\mathrm{TM}} 720 \mathrm{Li}$ and Inconel $738 \mathrm{LC}$ at low values of LMP and better creep properties than those of the Inconel 617 alloy at higher LMP values.
\end{abstract}

Key words: Linear friction welding, Ni-based superalloy, $\mathrm{AD} 730^{\mathrm{TM}}$, Mechanical properties at elevated temperatures, Creep mechanisms 


\section{Introduction}

Ni-based superalloys are widely used in the hot section of gas turbines, and consequently, are subjected to creep and/or fatigue damage during operation [1-3]. Therefore, improving their high temperature performance is of paramount importance for industry. Linear Friction Welding (LFW), which is an emerging technology for manufacturing and repairing of rotating gas turbine components, has many advantages, such as improving service life and reducing weight, over fir tree assembly. It has been reported that slotted blade/disk assemblies are susceptible to fatigue damage since fretting cracks initiate from the fir tree, while LFW joints can be free from such problems [4-7]. Therefore, LFW can be used as an alternative manufacturing technology for fir tree replacement. LFW has already been applied to Ti alloys for compressor (i.e. low temperature) operation applications, but not to high temperature components. Thus, there is a need to understand the properties of LFWed joints at elevated temperatures.

LFW is a solid state joining process free from micro-cracking or porosity defects as the temperature does not reach the fusion point of the alloy during this process. This process is divided into three stages [7]: I) the conditioning phase, during which samples are oscillated under a specific frequency and amplitude, and brought together under a small force and time; II) the frictional phase, where friction pressure increases and heat is generated at the interface; the material at the interface then becomes plastic, and is expelled out of the weld interface as a flash (this material loss from the weld interface causes the parts to be shortened); III) the forge phase, during which the amplitude decreases to zero, and the samples are brought and consolidated together.

Thermomechanical processes such as LFW involve substantial microstructural changes in Nibased superalloys. The occurrence of dissolution and subsequent re-precipitation of $\gamma^{\prime}$ precipitates during LFW play a key role in controlling the mechanical properties of these alloys $[8,9]$. The dynamic and post-dynamic recrystallization, as well as the dissolution of creep resisting phases during welding, are expected to have some adverse effects on creep properties $[2,10,11]$. Damodaram et al. reported that, a reduction in the average size and volume fraction of $\gamma^{\prime}$ precipitates led to a reduction in the mechanical properties of as-welded specimens [12]. They studied the tensile properties of as-weld and post-weld heat-treated (PWHT) conditions on continuous drive friction-welded Inconel 718 specimens. The postwelded samples provided better room temperature tensile properties than those of the as- 
welded samples. Chamanfar et al. [13] reported that the post-weld heat treatment of LFWed Waspaloy provides better hardness properties than what is seen in the as-weld condition. However, the tests in that case were performed at room temperature, and consequently, the results cannot be directly applied to creep properties at high temperatures. Therefore, in this study, post-weld heat treatment is performed on the as-welded samples, and their creep properties are compared to those of the as-welded specimens.

Steuer et al. and Shi et al. [14-16] evaluated the creep properties of the transient liquid phase bonding and brazed joints of two different Ni-based superalloys used for blade applications. They reported that an increase in the density of pores, brittle phases and impurities at the grain boundaries resulted in lower creep properties in the brazed samples. In addition, both the volume fraction and morphology of $\gamma^{\prime}$ particles at the grain boundary have significant impacts on the creep rupture life. Thus, a homogenous joint after heat treatment may lead to higher yield strength for bonded samples. To the knowledge of the authors, no study has covered the creep properties of LFWed Ni-based superalloys in as-weld or post-weld heat treated conditions.

This study thus aims to investigate the high temperature creep performance of linear friction welded $\mathrm{AD} 730^{\mathrm{TM}}$ in as-weld and post-weld conditions, in comparison to the base material. In addition, the creep life of LFWed $\mathrm{AD} 730^{\mathrm{TM}}$ is predicted by the Larson-Miller plot. The creep properties are compared with those of several other Ni-based superalloys, and the underlying damage mechanisms are discussed.

\section{Experimental Procedures}

The material used in this study was a wrought $\mathrm{AD} 730^{\mathrm{TM}}$ [17] produced by the Aubert and Duval company, Les Ancizes (France) site. Table I presents the chemical composition of the investigated material. The material was subjected to a post-forge heat treatment consisting in solutionizing at $1080^{\circ} \mathrm{C}$ for four hours, followed by air cooling. The as-received material had around $40 \% \gamma^{\prime}$ particles at room temperature in equilibrium condition [8].

For the LFW experiments, rectangular blocks measuring $26 \mathrm{~mm} \times 13 \mathrm{~mm} \times 37 \mathrm{~mm}$ (length $\times$ width $\times$ height $)$ were machined by wire electro-discharge machining $($ EDM) at the mid-radius of a forged bar having a $\sim 150 \mathrm{~mm}$ diameter. An FW34-E20 LFW machine at TWI, Cambridge, UK was used for welding. The welding parameters which resulted in a sound 
joint with axial shortening of $3.8 \mathrm{~mm}$ were as follows: frequency of oscillation of $40 \mathrm{~Hz}$, friction pressure of $285 \mathrm{MPa}$ and forge pressure of $580 \mathrm{MPa}$.

A PWHT consisting of solutionizing and aging was conducted on the LFWed specimens as follows: solutionizing at $900^{\circ} \mathrm{C}$ for two hours, heating at $0.15^{\circ} \mathrm{C} / \mathrm{s}$ to $1080^{\circ} \mathrm{C}$, held at this temperature for four hours followed by air cooling, and aging at $730^{\circ} \mathrm{C}$ for eight hours followed by air cooling. This last aging heat treatment is known to maximize the tensile strength in the $600-700^{\circ} \mathrm{C}$ temperature range, without affecting the creep strength of $\mathrm{AD} 730^{\mathrm{TM}}$ at $700^{\circ} \mathrm{C}$ in the fine grain state [3].

Creep tests were conducted in as-welded and PWHTed conditions on cylindrical samples having a diameter of $4 \mathrm{~mm}$ and a gage length of $14 \mathrm{~mm}$. Specimens were machined after PWHT (if any) by EDM, and then turned. A final mechanical polishing of the gage length up to a 4000 grade $\mathrm{SiC}$ was used to limit the surface roughness, and to avoid any surface recrystallization of the specimens due to surface residual stresses. Creep tests were performed in tension under constant load, and elongation was continuously monitored using a Linear Variable Displacement Transducer (LVDT). Creep tests were carried out under initial stresses of $600 \mathrm{MPa}$ and $750 \mathrm{MPa}$ at $700^{\circ} \mathrm{C}\left( \pm 1^{\circ} \mathrm{C}\right)$, and initial stresses of $100 \mathrm{MPa}$ and $200 \mathrm{MPa}$ at $850^{\circ} \mathrm{C}\left( \pm 1^{\circ} \mathrm{C}\right)$. These tests were performed at $700^{\circ} \mathrm{C}$ and $850^{\circ} \mathrm{C}$ to cover possible applications of $\mathrm{AD} 730^{\mathrm{TM}}$ alloy, such as high pressure turbine disks or seal rings for land-based gas turbine or aero-engines.

Macro and microstructural investigations were conducted after specimens were mounted and polished using standard metallographic techniques. For the microstructure characterization of as-welded samples, a mixture of Regia water ( $2 / 3$ vol. part) and distilled water ( $1 / 3$ vol. part) was used as an etchant. Microstructure evolution and fractographic observations were examined by optical microscopy (OM), Field Emission Gun Scanning Electron Microscopy (FEG-SEM) and JEOL 6400 SEM. The welds were investigated by FEG-SEM to examine the changes that occur in the microstructure during post-weld heat treatment, as well as to analyze the fracture surfaces. In order to characterize the nanometric size $\gamma^{\prime}$ precipitates, the secondary electron (SE) mode in Hitachi SU8230 SEM was used. The back-scattered electron (BSE) mode was used to record images from the polished surfaces of the samples. The energy dispersive spectroscopy (EDS) technique was performed to acquire local chemical composition and distribution maps of the different chemical elements constituting various phases along the fractured locations. Grains sizes were evaluated by analyzing EBSD maps 
obtained for 5 areas in the weld interface in as-welded and PWHT conditions. High angle boundaries in the misorientation range of $15-55^{\circ}$ were considered to estimate the grain size.

\section{Results and Discussion}

\subsection{Macroscopic and Microscopic Evaluation of the Joint after LFW}

Visual inspection of the weld interface (Fig. 1 (a)) showed that a bifurcated flash was formed during LFW, and that the flash is connected around the corners of the specimen, which is indicative of the high integrity of the joint in the LFWed sample. Examination of the weld by optical microscopy revealed that the weld line did not have any microcracks or impurities such as oxides, which can affect the mechanical properties or life of the weld (Fig. 1 (b)). Higher magnification of the weld revealed no oxide particles, voids or microcracks in the corner of the LFWed sample (Fig. 1 (c)).

Microstructure examination of the parent material showed a trimodal $\gamma^{\prime}$ size distribution composed of primary, secondary and tertiary $\gamma^{\prime}$ particles with average diameters of $1.4 \mu \mathrm{m}$, $30 \mathrm{~nm}$, and less than $10 \mathrm{~nm}$, respectively [8]. In contrast, a monomodal re-precipitated $\gamma^{\prime}$ distribution, less than $10 \mathrm{~nm}$ in size, was observed in the microstructure of the as-welded specimens in the weld line until $100 \mu \mathrm{m}$ from the weld interface (Fig. 2 (a)). As shown in Fig. 2 (a), primary $\gamma^{\prime}$ and boride particles are mostly dissolved at the weld interface, indicating that the weld interface experiences temperatures higher than boride and $\gamma^{\prime}$ solvus during LFW [18].

After post-weld heat treatment, the parent material showed a bimodal precipitate size distribution, containing primary and secondary $\gamma^{\prime}$ particles, having respectively average diameters of $1.5 \mu \mathrm{m}$ and $40 \mathrm{~nm}$, while the weld zone revealed a trimodal size distribution, as shown in Figs. 2 (b) and 2 (c). The obtained results show that subsolvus post-weld heat treatment led to coarsening of re-precipitated $\gamma^{\prime}$ particles formed during cooling in the weld zone after LFW. The morphology of the coarsened particles is cuboidal, and their average size and volume fraction were determined to be $230 \mathrm{~nm}$ and 4\%, respectively (Fig. 2 (c)). Higher magnification (insert in Fig. 2 (c)) shows that tertiary $\gamma^{\prime}$ particles were formed between the

cuboidal precipitates during cooling from $1080^{\circ} \mathrm{C}$, and that they coarsened during the aging heat treatment at $730^{\circ} \mathrm{C}$, as they were $40 \mathrm{~nm}$ in size after PWHT. Finally, grain size 
measurement revealed that the average grain size of the weld interface was about $8 \mu \mathrm{m}$ in PWHT condition, which is twice of that in the as-welded condition (Fig. 3).

\subsection{Creep Testing of PWHTed Joints at $700^{\circ} \mathrm{C}$ and $850^{\circ} \mathrm{C}$}

The creep behavior of specimens tested under $100 \mathrm{MPa}$ and $200 \mathrm{MPa}$ at $850^{\circ} \mathrm{C}$ and under $600 \mathrm{MPa}$ and $750 \mathrm{MPa}$ at $700^{\circ} \mathrm{C}$ are compared in Fig. 4 for the base material, as well as in the as-welded and post-weld heat-treated conditions. As shown in Figs. 4 (a) and (d), creep properties improved after the welded specimens were subjected to post-weld heat treatment. In order to observe the three stages of creep in uniaxial tension, the creep curves are plotted in the form of the instantaneous strain rate versus strain, as illustrated in Figs. 4 (b), (c), (e) and (f). The results demonstrate that at $700^{\circ} \mathrm{C}$ and $850^{\circ} \mathrm{C}$, the minimum creep strain rate decreases with decreasing applied stress. In these figures, a noticeable primary creep stage is observed for PWHTed condition at $700^{\circ} \mathrm{C}$ under both stress levels and at $850^{\circ} \mathrm{C}$ under stress level $200 \mathrm{MPa}$, as the strain rate decreases until a minimum true creep strain is reached.

The secondary creep stage is identified where the strain rate is approximately constant. As shown in Figs. 4 (a), (b) and (c), it is relatively easy to observe this stage for creep tests of the base material and under the PWHT condition at a temperature of $700^{\circ} \mathrm{C}$ under $600 \mathrm{MPa}$ and $750 \mathrm{MPa}$ stress levels. There is no clear secondary creep domain in the creep curve of the aswelded specimen since there is a continuous increase in the creep rate. This continuous acceleration of creep deformation is expected to result from a dynamic evolution of $\gamma^{\prime}$ precipitation during creep deformation.

During stage II, the creep rate is controlled by the balance between the strain hardening of the alloy due to deformation and thermal softening due to dislocations movement [19]. The tertiary creep regime can be seen at $700^{\circ} \mathrm{C}$ and $850^{\circ} \mathrm{C}$ as the strain rate begins to increase once again. It is worth mentioning here that the as-welded specimens did not exhibit any primary and secondary creep stages at $850^{\circ} \mathrm{C}$ creep test conditions. In addition, PWHTed specimens did not reveal any primary and secondary creep stages at $850^{\circ} \mathrm{C}$ under the $100 \mathrm{MPa}$ stress level. Their creep behavior consisted of continuous creep acceleration up to failure (see Figs. 4 (b), (c), (e) and (f)). This thus indicates an absence of any strain hardening mechanism, which will be elaborated in section 3.4.1 through microstructure analyses.

Figs. 5 (a)-(d) show the appearance of the cross section of PWHTed samples after rupture during creep tests at $700^{\circ} \mathrm{C}$ and $850^{\circ} \mathrm{C}$. More creep strain accumulation occurs during creep 
testing at $850^{\circ} \mathrm{C}$ compared to that at $700^{\circ} \mathrm{C}$. Microscopic observations showed that the fracture surface was mostly oxidized, especially after testing at $850^{\circ} \mathrm{C}$. In addition, SEM and optical observations showed that the failure initiated in the parent material during testing under $750 \mathrm{MPa}$ at $700^{\circ} \mathrm{C}$ and $100 \mathrm{MPa}$ at $850^{\circ} \mathrm{C}$, while it was in the weld zone after testing under $600 \mathrm{MPa}$ at $700^{\circ} \mathrm{C}$ and $200 \mathrm{MPa}$ at $850^{\circ} \mathrm{C}$. Although PWHTed samples exhibited failure initiation in the weld zone, their creep life was found to be comparable to that of the parent material, as illustrated in Fig. 4 (d). The specimens after failure at $850^{\circ} \mathrm{C}$ under $100 \mathrm{MPa}$, had a non-homogenous diameter due to the difference in grain size in the heat-affected area close to the weld joint. At this temperature, diffusion creep is mainly active for fine grain materials, with the grain boundary sliding acting as a rate controlling parameter for creep strains in excess of $1 \%$ [20-22]. The creep damage mechanisms in the LFWed samples will be discussed in detail in the following sections.

\subsection{Effect of PWHT on Larson-Miller Diagram}

The creep rupture characteristics of the base, as-welded and PWHTed materials are compared in Fig. 6 (a) in the form of a Larson-Miller diagram. Eq. (1) is used to plot creep strength data as a function of a Larson-Miller Parameter (LMP) [1]:

$L M P=T[20+\log (t)] \times 10^{3}$

where $T$ is the absolute temperature in Kelvin and $t$ is the creep time to failure in hours. The diagram, presented in Fig. 6, shows that at high values of $L M P=23.3 \times 10^{3}-25.3 \times 10^{3}$ (high temperatures, low loads), base and PWHTed materials have similar characteristics. However, at lower values of LMP (low temperatures, high loads), the base material has higher strength than that of as-welded and PWHTed conditions. Testing conditions for the homogeneous fine grain parent $\mathrm{AD} 730^{\mathrm{TM}}$ are $700^{\circ} \mathrm{C} / 950 \mathrm{MPa}, 700^{\circ} \mathrm{C} / 850 \mathrm{MPa}, 700^{\circ} \mathrm{C} / 800 \mathrm{MPa}, 700^{\circ} \mathrm{C} / 750 \mathrm{MPa}$, $700^{\circ} \mathrm{C} / 700 \mathrm{MPa}, \quad 700^{\circ} \mathrm{C} / 600 \mathrm{MPa}, \quad 850^{\circ} \mathrm{C} / 250 \mathrm{MPa}, \quad 850^{\circ} \mathrm{C} / 200 \mathrm{MPa}, \quad 850^{\circ} \mathrm{C} / 100 \mathrm{MPa}$ and $850^{\circ} \mathrm{C} / 50 \mathrm{MPa}$.

The creep life values and creep rupture characteristics obtained in the present study (Figs. 4 and 6) indicate that the PWHTed specimens have higher creep life and strength than those of as-welded specimens for all test conditions and LMP values. Crack propagation is mainly associated with the joint microstructure in as-welded samples. It has been reported that if creep is controlled by diffusion, the creep strain rate is proportional to $1 /(\text { grain size })^{2}$ or $1 /(\text { grain size })^{3}$, depending on whether the diffusion is along grain boundaries or within the 
grain bulk during creep tests [23]. Microstructural examination results reported in Fig. 3 indicate that the average grain size in the weld interface is about $4 \mu \mathrm{m}$ in the as-welded condition, while it is about $8 \mu \mathrm{m}$ in the PWHTed condition. Thus, the creep strain rate of the weld interface in as-welded samples will be about four or eight times larger than that of the PWHTed samples, therefore leading to lower creep life for the as-welded samples.

Furthermore, the creep crack growth rate, CCGR is inversely proportional to the grain size, $d$, as follows [24]:

$C C G R=\frac{A K^{2}}{d}$

where $K$ is the stress intensity factor and $A$ is a material constant. Therefore, the crack growth rate should be higher in small grain size samples such as the as-welded samples based on Eq. (2).

The creep rupture properties of PWHTed $\mathrm{AD} 730^{\mathrm{TM}}$ are compared to those of Udimet ${ }^{\mathrm{TM}} 720 \mathrm{Li}$ (U720 Li) [25], Inconel 738LC (IN 738LC) [26] and Inconel 617 (IN 617) [27] by a LarsonMiller plot, as shown in Fig. 6 (b). The plot shows that PWHTed AD730 ${ }^{\mathrm{TM}}$ has similar characteristics as U720 Li and IN 738LC at low values of LMP (low temperatures and high stresses). The diagram also shows that the PWHTed sample has an advantage over the IN 617 alloy, while the IN 738LC alloy boasts higher LMP characteristics, LMP $=22 \times 10^{3}-26 \times 10^{3}$, at high temperatures and low stresses. This could be due to the fact that IN 738LC has a higher $\gamma^{\prime}$ volume fraction than $\mathrm{AD} 730^{\mathrm{TM}}$ in this temperature range (IN 738LC has a $45 \% \gamma^{\prime}$ volume fraction, which is $5 \%$ higher than that of $\mathrm{AD} 730^{\mathrm{TM}}$ ), and larger grains, since it is a cast alloy, while IN 617 alloy has a lower volume fraction of $\gamma^{\prime}$ as compared to AD730 ${ }^{\mathrm{TM}}$. The IN 617 alloy is mainly a solution-hardened $\mathrm{Ni}$ - based alloy with a very low $\gamma^{\prime}$ volume fraction of about $4 \%$.

\subsection{Microstructure Analysis of PWHTed Joints}

\subsubsection{Deformation and Damage Mechanism during Creep}

a) $700^{\circ} \mathrm{C}-600 \mathrm{MPa}$

The fractographic features of the creep-tested specimen at $700^{\circ} \mathrm{C}$ under $600 \mathrm{MPa}$ are shown in Figs. 7 and 8. Fig. 7 (a) shows that the fracture surface is almost flat. An analysis of this flat 
surface at higher magnification (Fig. 7 (b)) revealed dimples throughout the fracture surface, indicating a ductile fracture. Parallel strips observed on the fracture surface at low magnification (Fig. 7 (a)) and a multimodal size distribution of $\gamma^{\prime}$ particles on the longitudinal fracture surface (Fig. 8 (a)) are specific to a fracture at the weld zone.

Cavities initiate preferentially in the weld zone at the grain boundaries due to the nucleation of voids around the primary $\gamma^{\prime}$ or carbide precipitates and the decohesion of these particles, as shown in Fig. 8. Furthermore, the growth and coalescence of voids, nucleated at grain boundaries connected to the surface, assist surface creep crack growth (Fig. 7 (c)). As reported in Fig. 2 (b), primary $\gamma^{\prime}$ precipitates are largely dissolved in the weld zone during LFW. Therefore, grain boundaries have the weakest configuration in the weld region, and microcracks could easily propagate in this zone due to a lack of borides and primary $\gamma^{\prime}$ particles at the grain boundaries (Fig. 8 (b)). It is worth noting that while grain boundaries are the preferred crack initiation sites, as shown in Fig. 8 (c), some cavities at the interface of coarse secondary $\gamma^{\prime}$ coalesced and formed continuous intergranular cracks.

\section{b) $700^{\circ} \mathrm{C}-750 \mathrm{MPa}$}

Fig. 9 (a) shows the fracture surface of the sample tested at $700^{\circ} \mathrm{C}$ under the highest stress used in this investigation. The surface is characterized by flat regions of dimpled, ductile appearing fracture in the parent material. In contrast, in the zones adjacent to the weld zone, shiny shear lips are visible, and are formed on bands oriented at $\pm 45^{\circ}$ to the sample thickness. An examination of the fracture surface also indicates that cracks initiate mainly from oxidized carbide particles in the parent material at the surface and propagate through grain boundaries (Figs. 9(b) and (c)). The presence of primary $\gamma^{\prime}$ particles, as indicated by arrows in Fig. 9 (d), and oxidized grain boundaries (Fig. 9 (c)) at the fracture surface indicate that crack propagation is initially intergranular, and occurs in the parent material. Since oxide particles are brittle, creep cracks could initiate very easily from the interface of oxides located at grain boundaries connected to the surface. Then, oxygen diffusion ahead of the crack can weaken the grain boundary and aid intergranular crack propagation in the early stages.

Thermocalc simulation [8] showed that the microstructure of $\mathrm{AD} 730^{\mathrm{TM}}$ contains about $37 \% \gamma^{\prime}$ at $700^{\circ} \mathrm{C}$. An examination of the fracture surface in the longitudinal direction revealed that nucleation and growth of pores occurred through diffusion at the interface of the matrix and second-phase particles (Figs. 9 (e) and (f)). This is generally related to dislocation pile-up 
at the interface [28]. Therefore, the first mode of fracture, as shown in Fig. 9, is grain boundary sliding controlled by diffusion and assisted by oxidation. Testing at $700^{\circ} \mathrm{C}$ under $750 \mathrm{MPa}$ stress, compared to that at $700^{\circ} \mathrm{C}$ under $600 \mathrm{MPa}$ stress will generate more dislocations, increasing the propensity for transgranular fracture by linkage of these dislocations. Therefore, crack propagation leads to faster fracture of regions at a $\pm 45^{\circ}$ angle relative to the applied stress direction, as suggested by the shiny zones at the fracture surface, as shown in Fig. 9 (a).

\section{c) $850^{\circ} \mathrm{C}-100 \mathrm{MPa}$}

During creep tests at $850^{\circ} \mathrm{C}$ under $100 \mathrm{MPa}$, all specimens fail in the base material far from the weld zone. Fractographic analyses reveal that the specimens neck in the parent material before fracture (Fig. 10 (a)). As soon as necking starts, deformation is concentrated in the neck, and triaxiality of local applied stress increases due to the geometry of the neck [29]. This causes excessive growth and a coalescence of microvoids at the center of the neck and very high levels of creep elongation, as shown in Figs. 10 (a) and (b) and Fig. 5 (c). An analysis of the fracture surface in the longitudinal direction, presented in Figs. 10 (c) and (d), reveals that cellular $\gamma^{\prime}$ particles and precipitate-free zones (PFZ) are formed adjacent to grain boundaries. The absence of an efficient $\gamma^{\prime}$ precipitation close to the GB probably explains the continuous acceleration of the creep curve (Figs. 4 (e) and (f)). Cellular or discontinuous coarsening occurs when $\gamma^{\prime}$ particles coarsen perpendicularly to a moving grain boundary [30]. Then, solute diffusion along the grain boundary accelerates the growth of these particles, and as a result, a PFZ is formed. The morphology of $\gamma^{\prime}$ particles is lamellar after coarsening (Figs. 10 (c) and (d)). An examination of the fracture surface in the transverse and longitudinal directions (Fig. 10) shows that cracks initiate and propagate inside the PFZ due to strain accumulation in this soft area.

Furthermore, EDS mapping results and chemical analyses of the area adjacent to the grain boundary, presented in Fig. 11, reveal chromium enrichment at the grain boundaries. On the other hand, at such high temperatures, oxygen diffuses very rapidly along grain boundaries connected to the surface, and with the high affinity of chromium for oxygen, chromium oxides are formed, as shown in Figs. 10 (e) and 11 (c). The low ductility of the oxide layer results in its rupture under loading, which induces crack nucleation, and exposes fresh metallic material to the environment. Crack propagates due to oxide-induced crack growth. 
Therefore, as Figs. 10 and 11 show, the fracture mechanism is intergranular, assisted by diffusion and oxidation. The shape of the specimen after failure (Fig. 5 (c)) is indicative of the heterogeneity in grain size. A coarser grain area in HAZ leads to slower creep, and thus, to a smaller reduction in the diameter and less elongation in this area. It is also worth mentioning that the increase in grain size has been shown to be very effective in improving the creep strength in the $\mathrm{AD} 730^{\mathrm{TM}}$ alloy at $850^{\circ} \mathrm{C}[31,32]$.

d) $850^{\circ} \mathrm{C}-200 \mathrm{MPa}$

Multimodal size distribution of $\gamma^{\prime}$ precipitates and parallel strips, shown in Fig. 12, point to a fracture in the weld zone. However, creep test results (Figs. 4 and 6) show that LMP and creep life of the joints are about $23.8 \times 10^{3}$ and 14 hours, respectively, which are approximately comparable to those of the base metal. Fig. 12 shows that during creep tests at $850^{\circ} \mathrm{C}$ under $200 \mathrm{MPa}$, PFZ are formed close to grain boundaries. EDS mapping results presented in Fig. 13 show oxides and cracks formed at the grain boundaries. PFZs are formed due to solute elements absorption by intergranular $\gamma^{\prime}$ precipitates, and are weak and less resistant to oxidation. Thus, cavities, and therefore, chromium oxides (Fig. 13), are formed more easily in the weak regions than in the matrix. Then, these grain boundary cavities and oxides accelerate the intergranular cracking. Fig. 12 shows secondary microcracks initiated from the cavities inside the precipitate-free zone, and crack branching develops during propagation due to severe oxidation of the grain boundary. The connection of several grain boundary cracks leads to decohesion of the grain from the matrix, as shown in Fig. 12 (b).

\section{Conclusions}

The creep behavior of the LFWed AD730 ${ }^{\mathrm{TM}}$ was investigated in as-welded and PWHTed conditions under $100 \mathrm{MPa}$ and $200 \mathrm{MPa}$ at $850^{\circ} \mathrm{C}$, and $600 \mathrm{MPa}$ and $750 \mathrm{MPa}$ at $700^{\circ} \mathrm{C}$. The findings are summarized as follows:

1- A specific PWHT was developed for an LFWed fine grain $\mathrm{AD} 730^{\mathrm{TM}}$ alloy. It resulted in superior creep strength compared to that of as-welded joints.

2- A high LMP value $\left(24.5 \times 10^{3}\right)$ of the PWHTed AD730 ${ }^{\mathrm{TM}}$ compared to the IN 617 alloy indicates a good service life under high temperature and low stresses. 
3- The nucleation of voids around precipitates and the decohesion of these particles at oxidized grain boundaries connected to the surface assist surface creep crack growth at $700^{\circ} \mathrm{C}$. 4- Cracks initiate inside the PFZ at the grain boundaries, and propagate due to oxide-induced crack growth at $850^{\circ} \mathrm{C}$.

\section{Acknowledgements}

Financial support from the Natural Sciences and Engineering Research Council (NSERC) 261712 of Canada in the form of a Discovery Grant is gratefully acknowledged. The authors

express appreciation to Aubert \& Duval Co. for providing AD730 ${ }^{\mathrm{TM}}$ samples, and to TWI Ltd. for carrying out the LFW of the samples.

\section{References}

[1] Reed RC. The Superalloys: Fundamentals and Applications. New York: Cambridge University Press; 2006.

[2] Cormier J, Milhet X, Mendez J, Acta Mater. 2007;55:6250.

[3] Devaux A, Helstroffer A, Cormier J, Villechaise P, Douin J, Hantcherli M, Pettinari-Sturmel F. TMS Superalloys 2014: 521.

[4] Okazaki M, Ohtera I, Harada Y. Metall. Trans. A 2004; 35A:535.

[5] Preuss M, Withers PJ, Baxter GJ. Mater. Sci. Eng. A 2006; 437:38.

[6] Mary C, Jahazi M, Adv. Mater. Research 2007;15-17:357.

[7] Chamanfar A, Jahazi M, Cormier J. Metall. Mater. Trans A 2015;46 (4):1639.

[8] Masoumi F, Jahazi M, Shahriari D, Cormier J. J. Alloys Compd. 2016;658:981.

[9] Masoumi F, Shahriari D, Jahazi M, Cormier J, Devaux A. Sci. Rep. 6, 28650; doi : 10.1038/ srep28650 (2016).

[10] Cormier J, Cailletaud G. Mater. Sci. Eng. A 2010;527:6300.

[11] Le Graverend JB, Cormier J, Jouiad M, Gallerneau F, Hamon F. Mater. Sci. Eng. A 2010;527: 5295.

[12] Damodaram R, Ganesh Sundara Raman S, Prasad Rao K. Mater. Design 2014;53:954.

[13] Chamanfar A, Jahazi M, Gholipour J, Wanjara P, Yue S. Metall. Mater. Trans. A 2011;42A:729.

[14] Steuer S, Singer RF. Metall Mater Trans A 2014; 45(8): 3545.

[15] Steuer S, Piegert S, Frommherz M, Singer RF, Scholz A. Adv. Mater. Research 2011;278:454.

[16] Shi D, Dong C, Yang X, Zhang L, Hou J, Liu Y. Mater. Sci. Eng. A 2012;545:162. 
[17] Devaux A, Picque B, Gervais MF, Georges E, Poulain T, Heritier P, TMS Superalloys 911 (2012).

[18] Masoumi F, Shahriari D, Jahazi M, Cormier J, Flipo BCD. Metall. Mater. Trans. A 2017; 48: 2886.

[19] Riedel H. Fracture at High Temperatures. Berlin: Springer;1986.

[20] Thibault K, Locq D, Caron P, Boivin D, Renollet Y, Bréchet Y. Mater. Sci. Eng. A 2013;588:14.

[21] Soula A, Locq D, Boivin D, Renollet Y, Caron P, Bréchet Y. J. Mater. Sci. 2010;45(20):5649.

[22] Soula A, Renollet Y, Boivin D, Pouchou JL, Locq D, Caron P, Bréchet Y. Mater. Sci. Eng. A 2009;510-511:301.

[23] Bano N, Koul AK, Nganbe M. Metall Mater Trans A 2014;45A:1928.

[24] Xu S, Koul AK, Dickson JI. Metall. Trans. A 2001;32A:795.

[25] Gu YF, Cui C, Ping D, Harada H, Fukuda T, Fujioka J. Mater. Sci. Eng. A 2009;510-511:250.

[26] Houa JS, Guoa JT, Zhoua LZ, Yuana C, Ye HQ. Mater. Sci. Eng. A 2004;374:327.

[27] Nandi S, Reddy JG, Singh K. Procedia Eng. 2014;86:66.

[28] Frost H, Ashby M, Deformation-mechanism maps, The plasticity and creep of metals and ceramics, Oxford: Pergamon Press; 1982.

[29] Rogers HC. Ductility. Metals Park. OH: ASM;1968:31.

[30] Maldonado R, Nembach E. Acta Mater. 1997;45:213.

[31] Thébaud L, Villechaise P, Cormier J, Crozet C, Devaux A, Béchet D, Franchet JM, Organista A, Hamon F. Metals 5, 2236; doi:10.3390/met5042236 (2015)

[32] Michel HT, Reda LS, Santos GE, Cormier J, Dumont C, Villechaise P, Bocher P, Texier D, Georges E, Bridier F, Hamon F, Devaux A. TMS Superalloys 539 (2016). 


\section{$\underline{\text { List of Tables }}$}

Table I. Chemical composition of AD730 ${ }^{\mathrm{TM}}$ (wt\%) [17]

\begin{tabular}{cccccccccccc}
\hline $\mathrm{Ni}$ & $\mathrm{Fe}$ & $\mathrm{Co}$ & $\mathrm{Cr}$ & $\mathrm{Mo}$ & $\mathrm{W}$ & $\mathrm{Al}$ & $\mathrm{Ti}$ & $\mathrm{Nb}$ & $\mathrm{B}$ & $\mathrm{C}$ & $\mathrm{Zr}$ \\
\hline Base & 4 & 8.5 & 15.7 & 3.1 & 2.7 & 2.25 & 3.4 & 1.1 & 0.01 & 0.015 & 0.03 \\
\hline
\end{tabular}




\section{$\underline{\text { List of Fiqures }}$}

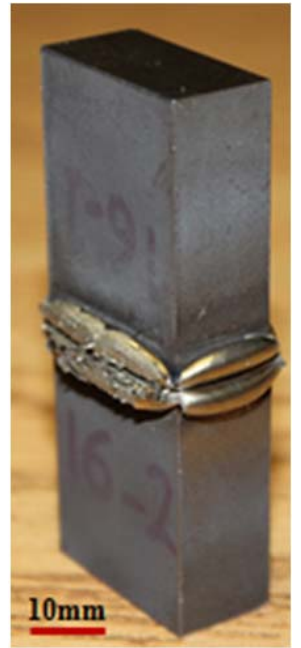

a)

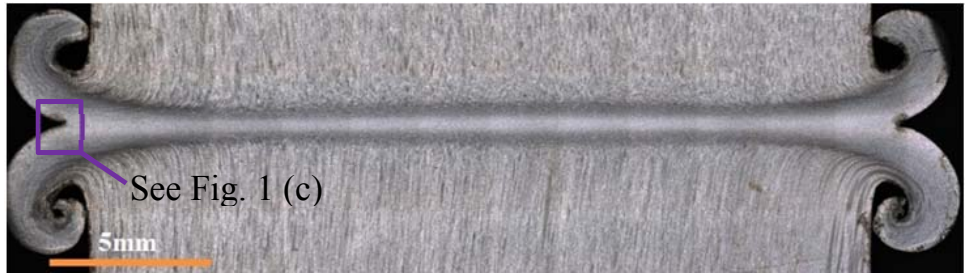

b)

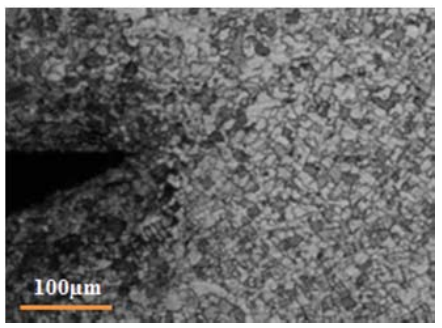

c)

Fig. 1 a) A photograph of LFWed sample b) a low magnification optical image of the welded sample showing integrated joint with no defects or impurities in the weld line $\mathrm{C}$ ) higher magnification of flash corner showing no microcracks or oxide particles.

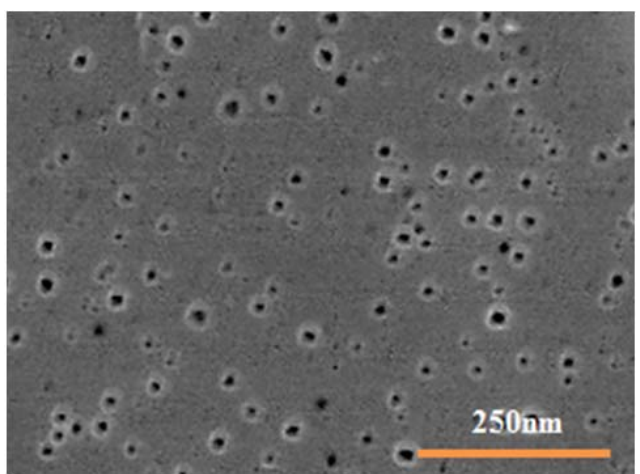

a)
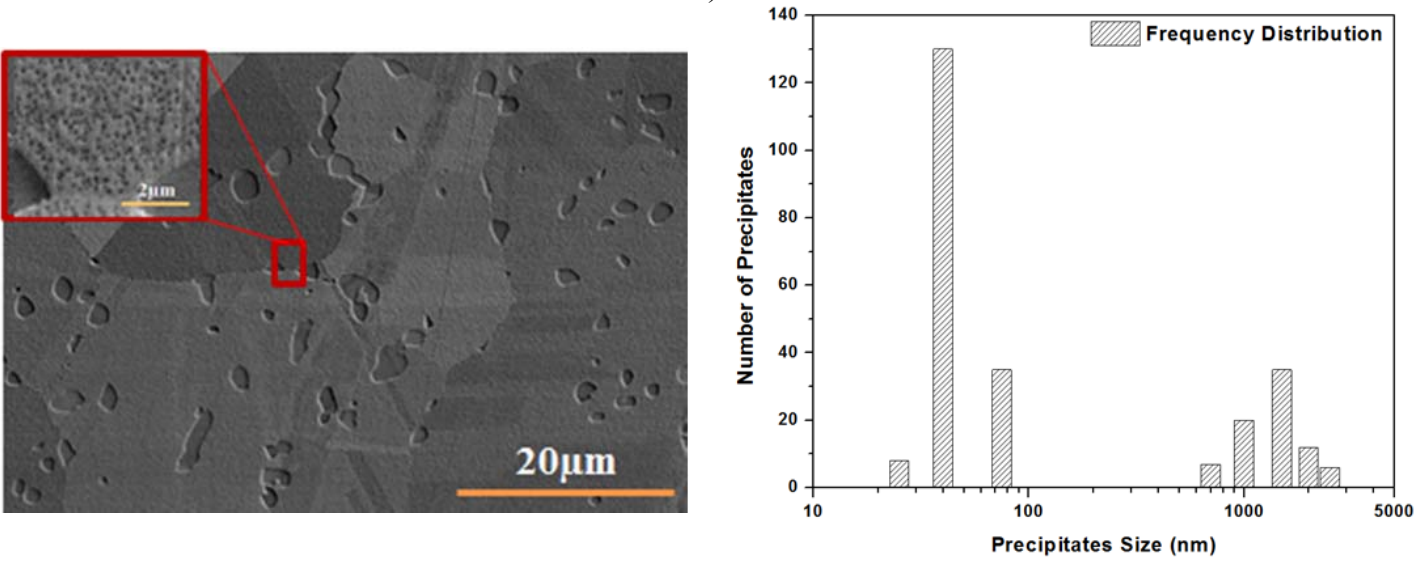

b) 

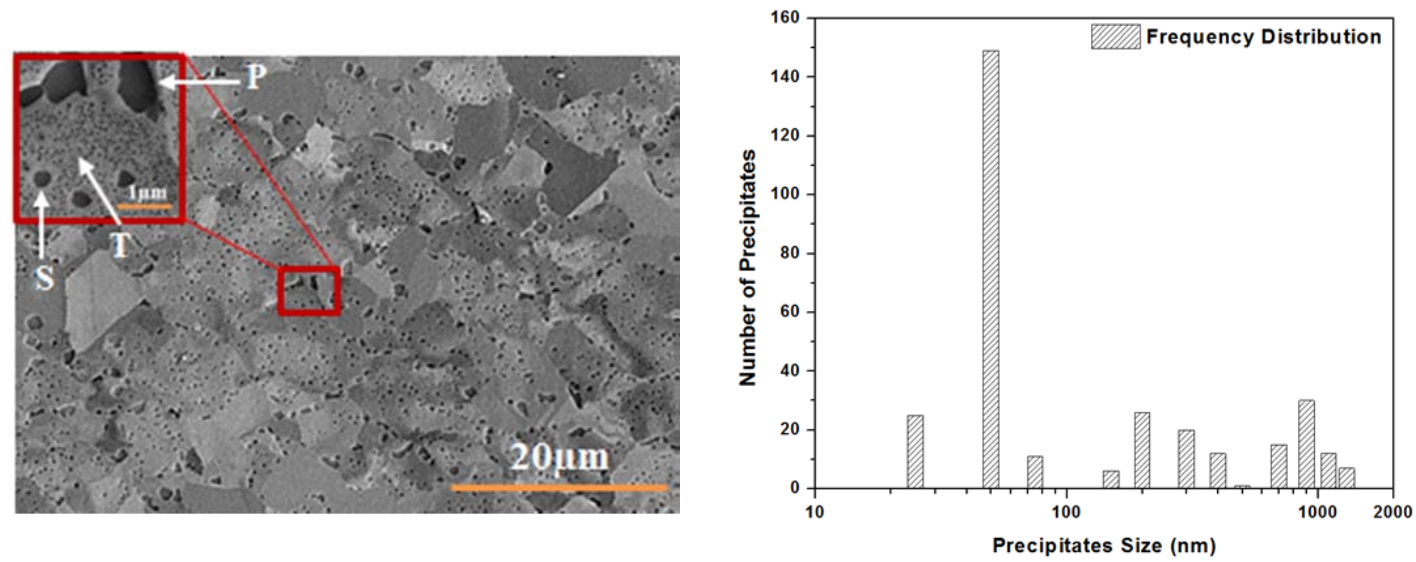

c)

Fig. 2. Microstructure of LFWed specimens in: a) weld line in as-welded condition b) parent material and c) weld zone (100 $\mu \mathrm{m}$ from the weld interface) in PWHTed condition. Primary (P), secondary (S) and tertiary (T) $\gamma^{\prime}$ precipitates have been shown by white arrows. $\gamma^{\prime}$ size distribution of the parent material and the weld zone after PWHT are presented respectively in (b) and (c).

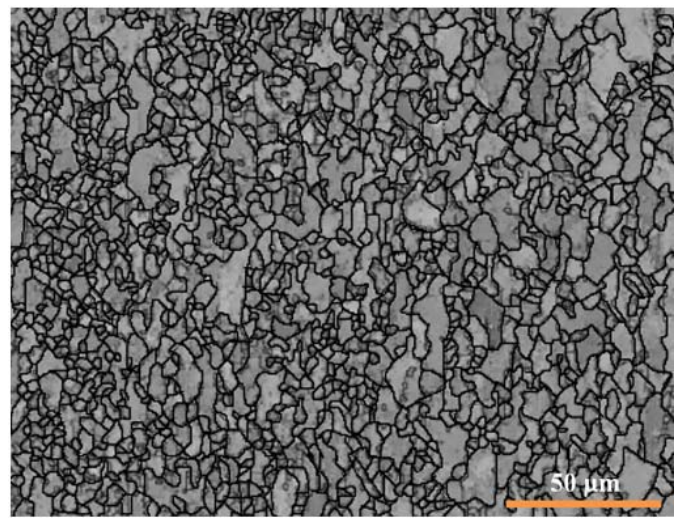

a)

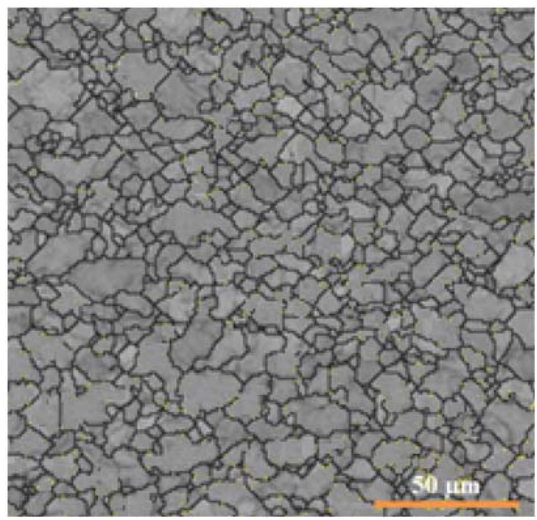

b)

Fig. 3. Microstructure of a LFWed $\mathrm{AD} 730^{\mathrm{TM}}$ at the weld line in: a) as-welded b) post welded conditions. 


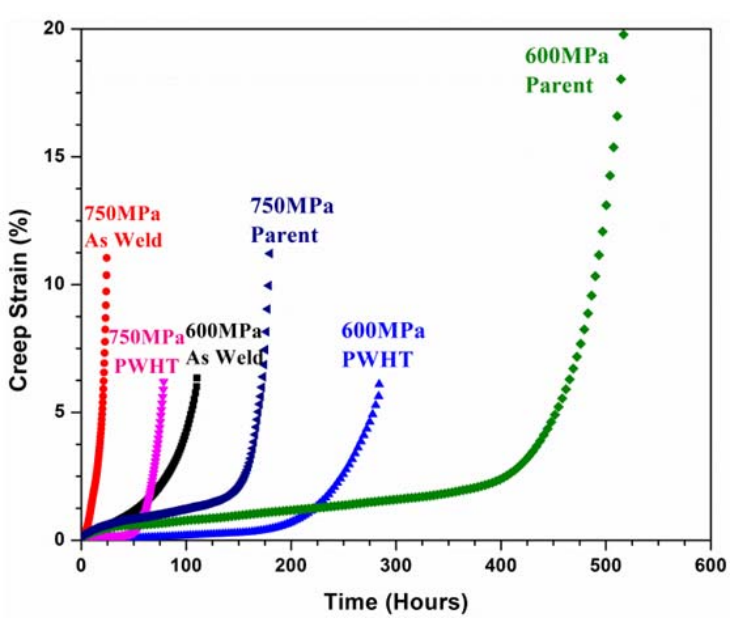

a)

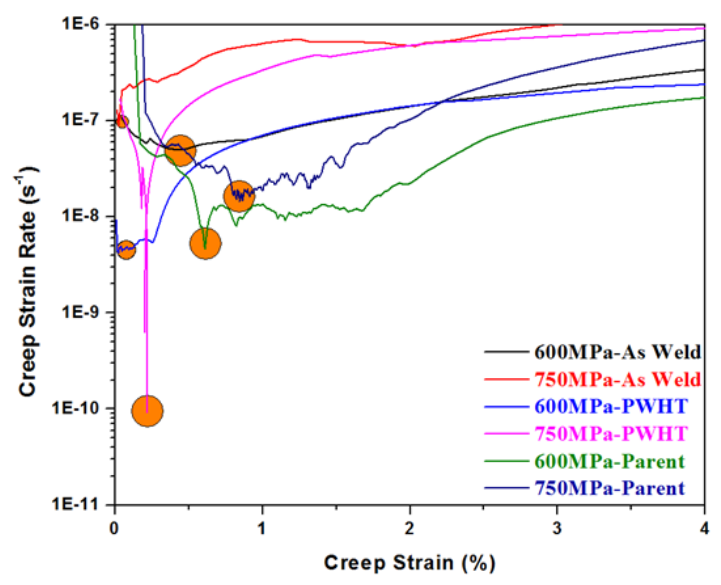

c)

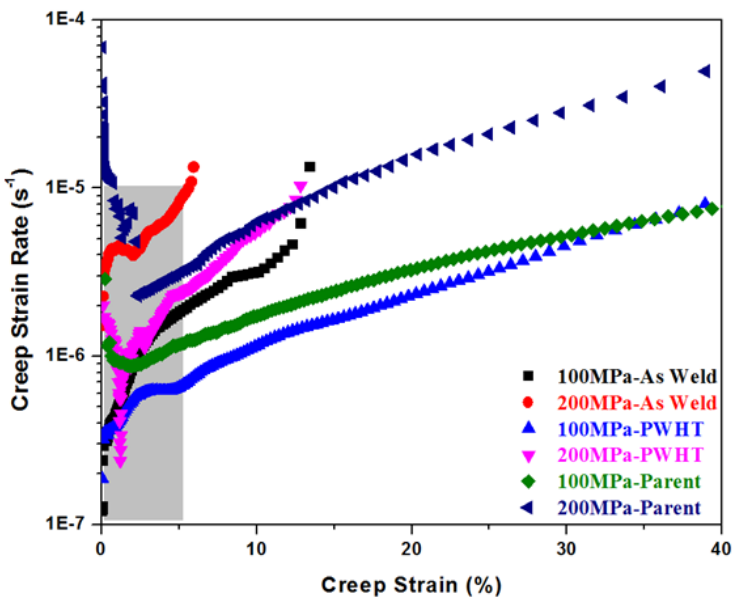

e)

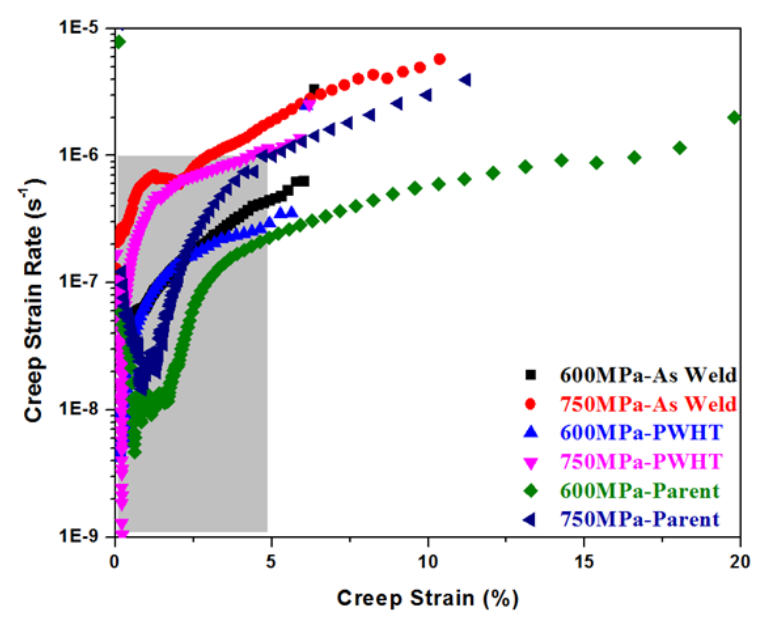

b)

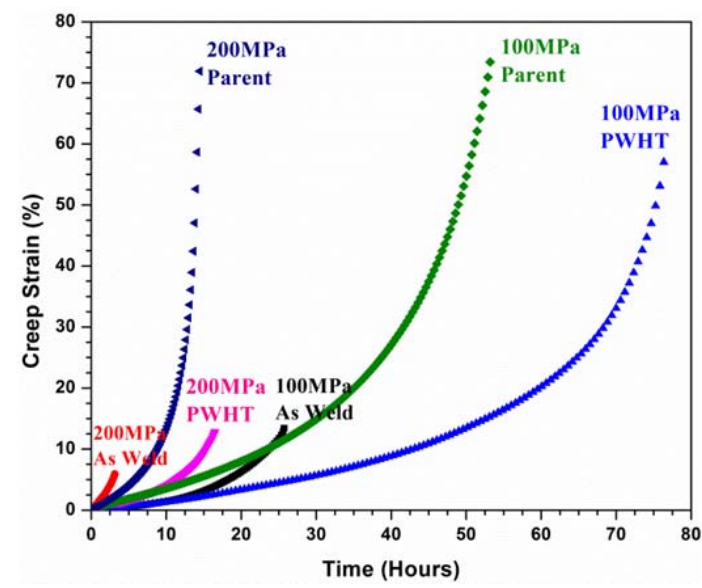

d)

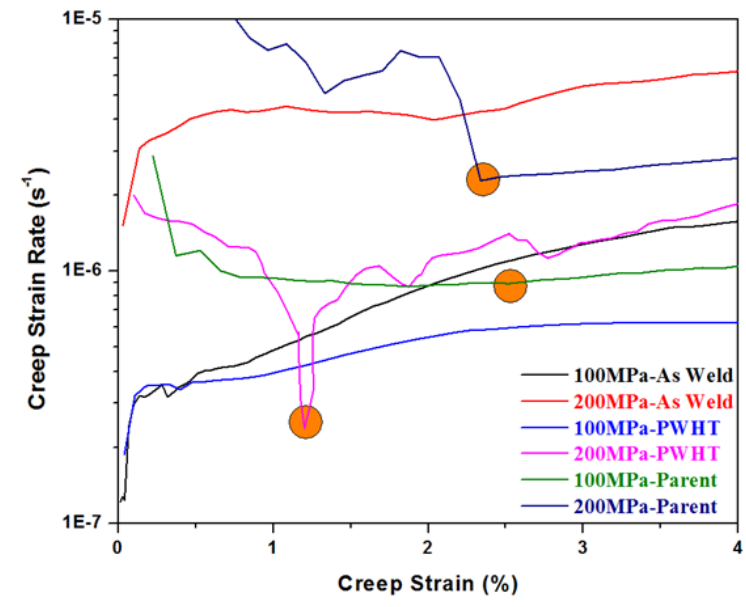

f)

Fig. 4. Creep curves of base material and LFWed specimens in as-welded and PWHTed conditions at a) \& b) \& c) $700^{\circ} \mathrm{C}$ under $600 \mathrm{MPa}$ and $750 \mathrm{MPa}$ d) \& e) \& f) $850^{\circ} \mathrm{C}$ under $100 \mathrm{MPa}$ and $200 \mathrm{MPa}$. Strain rate vs. strain data, shown in b) \& c) \& e) \& f), are used to reveal various stages of creep tests. Shaded zone is magnified to indicate the absolute minimum of the curves, as shown by filled circles. 


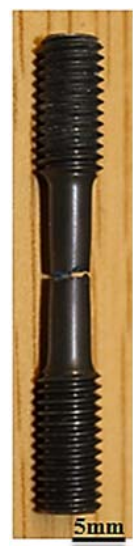

a)

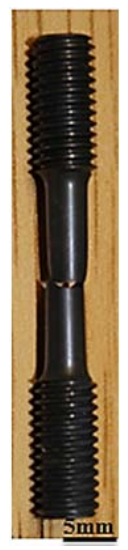

b)

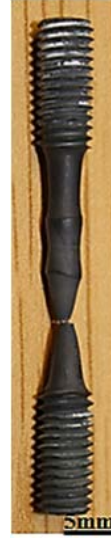

c)

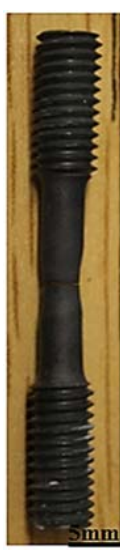

d)

Fig. 5. Appearance of the cross section of PWHTed samples after rupture during creep tests at a) $700^{\circ} \mathrm{C} / 600 \mathrm{MPa}$

b) $700^{\circ} \mathrm{C} / 750 \mathrm{MPa}$

c) $850^{\circ} \mathrm{C} / 100 \mathrm{MPa}$

d) $850^{\circ} \mathrm{C} / 200 \mathrm{MPa}$.

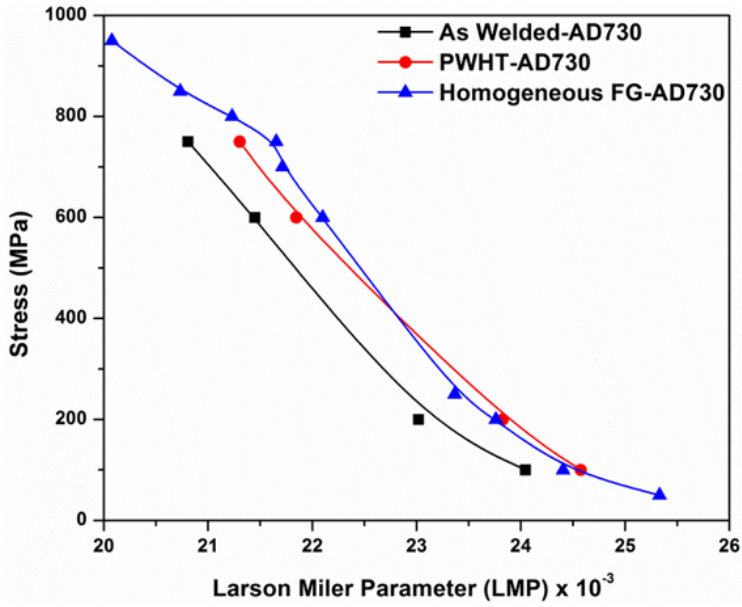

a)

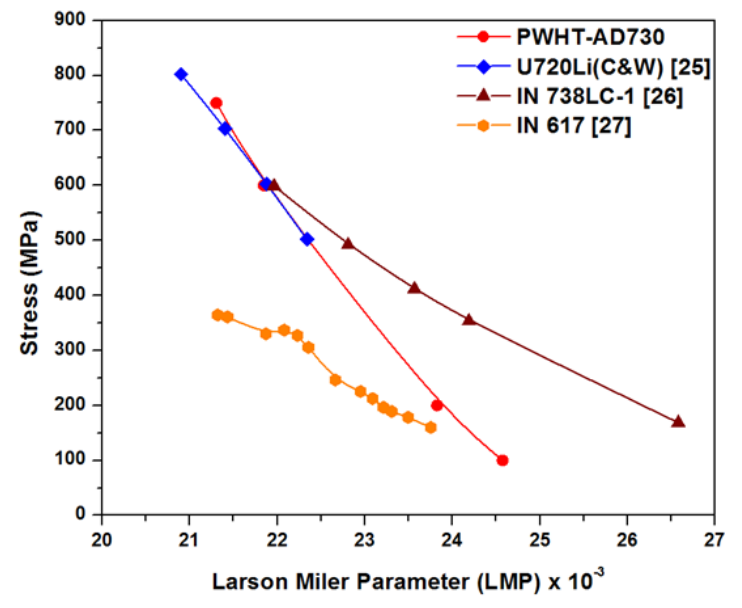

b)

Fig. 6. Comparison of Larson Miller parameter (LMP) for a) base metal, as-welded and PWHTed samples of AD730 $0^{\mathrm{TM}}$ b) PWHTed AD730 ${ }^{\mathrm{TM}}$, U720Li, IN $738 \mathrm{LC}$ and IN 617. 


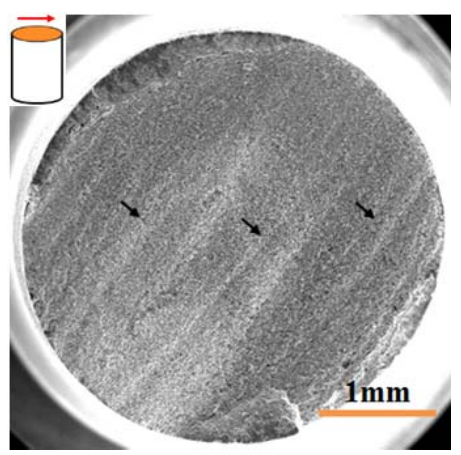

a)

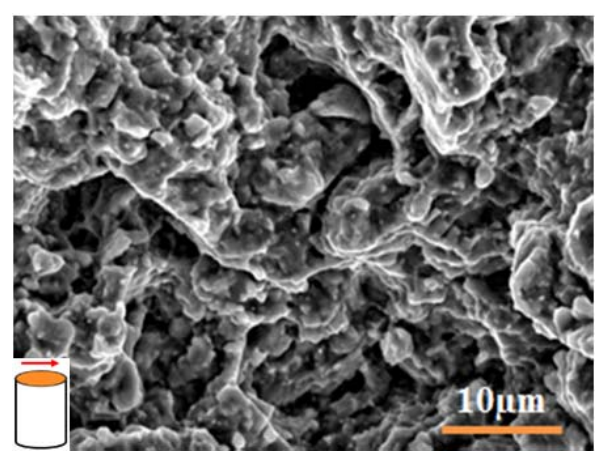

b)

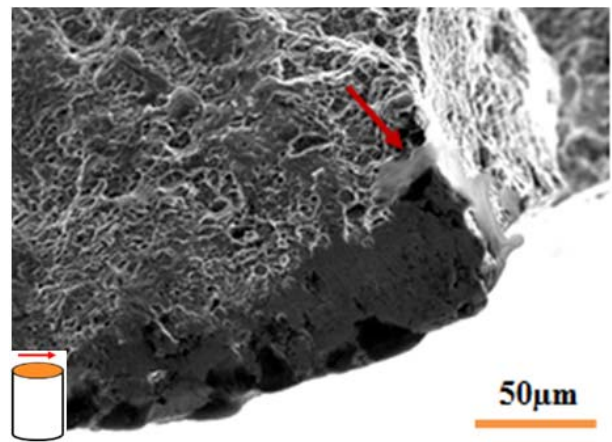

c)

Fig. 7. Fracture surface of the creep tested specimen at $700^{\circ} \mathrm{C}$ under $600 \mathrm{MPa}$ showing a) parallel strips on flat fracture surface, as marked by black arrows b) dimples and intergranular fracture c) oxidized layer at the fracture surface, as marked by red arrow. Transverse direction is shown by brown color.

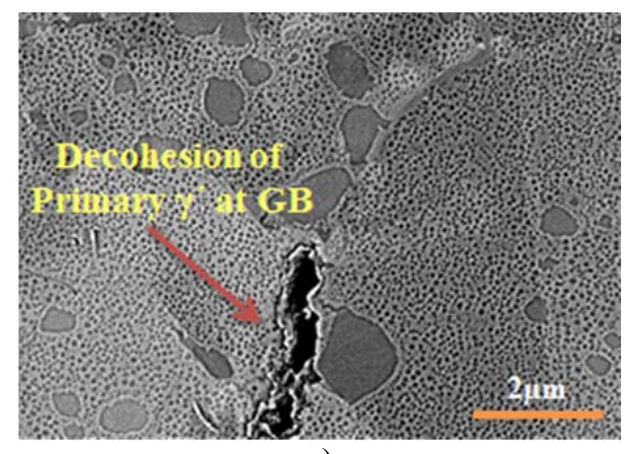

a)

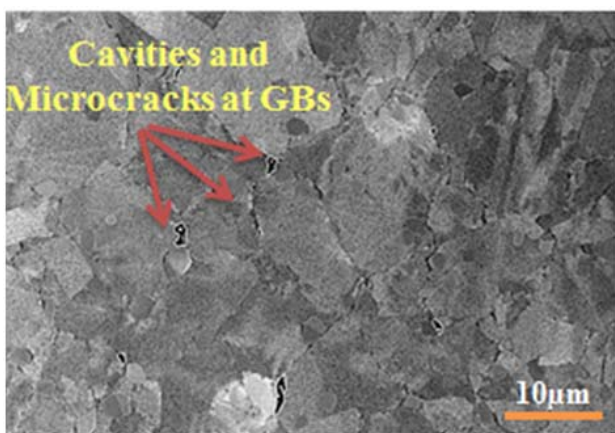

b)

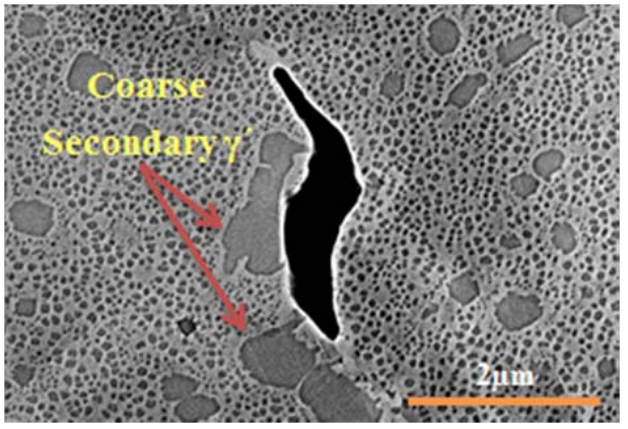

c)

Fig. 8. Post-failure observations on longitudinal cut from the creep tested samples at $700^{\circ} \mathrm{C} / 600$ MPa showing a) decohesion of primary $\gamma^{\prime}$ b) cavities and microcracks at GB c) Cavities at the interface of coarse secondary $\gamma^{\prime}$. Longitudinal direction is shown by brown color. 


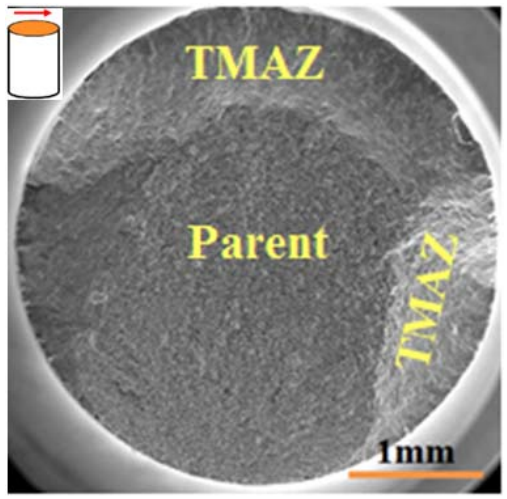

a)

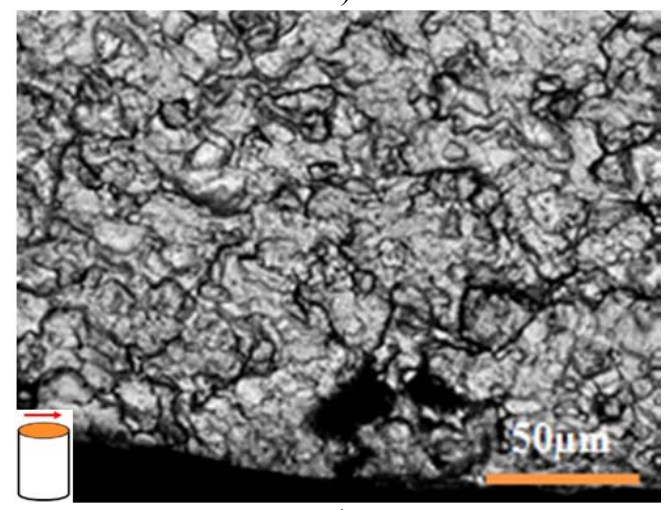

c)

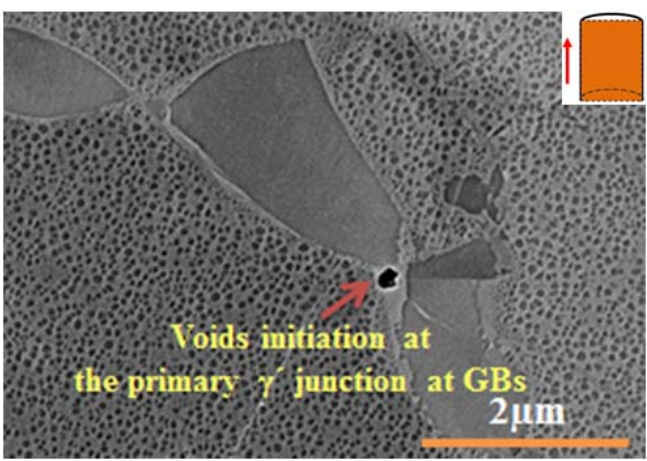

e)

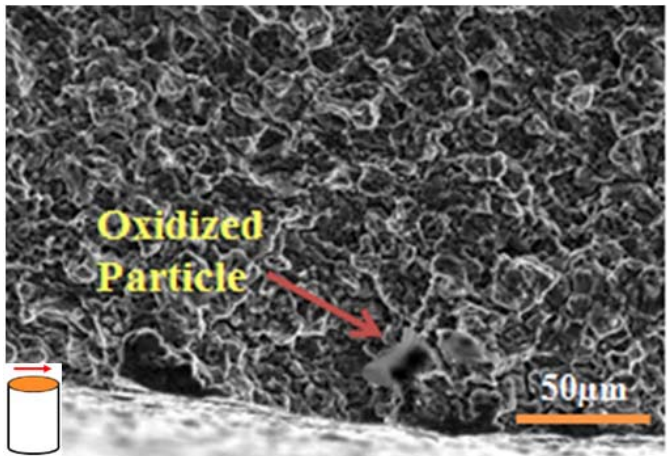

b)

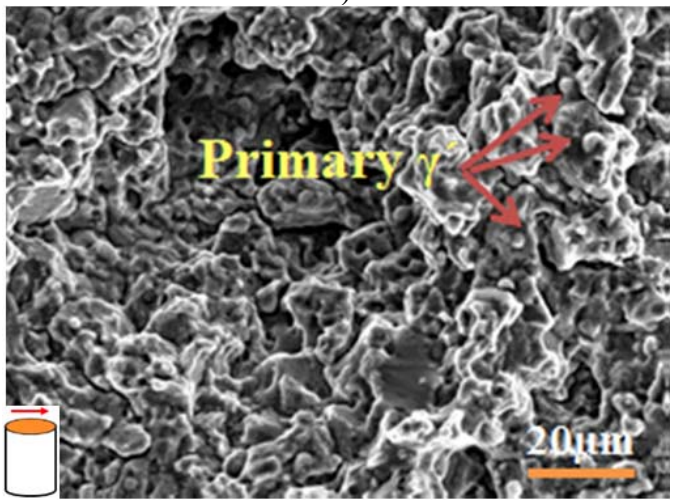

d)

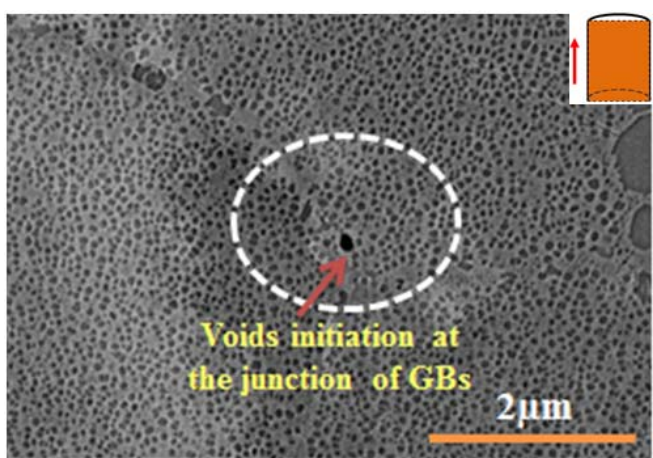

f)

Fig. 9. Post-failure transverse and longitudinal observations of the creep tested specimen at $700^{\circ} \mathrm{C} / 750 \mathrm{MPa}$ test condition showing a) initiation of crack at parent material and propagation adjacent to the weld zone, at the thermomechanically affected zone (TMAZ) b) and c) crack initiation from oxidized secondary particle and intergranular fracture e and f) pore nucleation at the primary $\gamma^{\prime}$ and the matrix interface or at the junction of GB. Transverse and longitudinal directions are shown by brown color. 


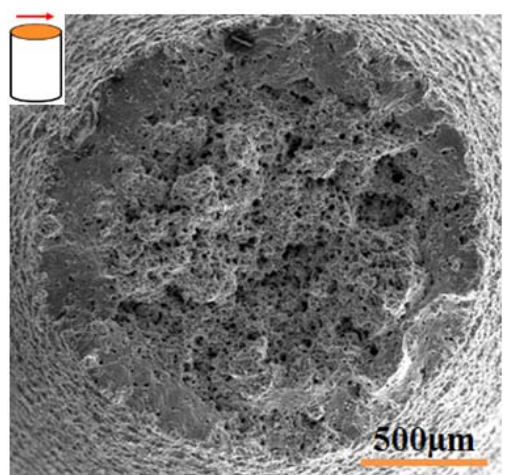

a)

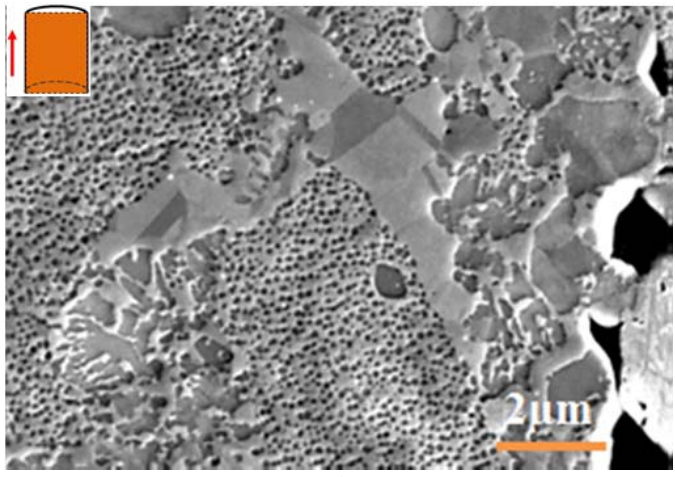

c)

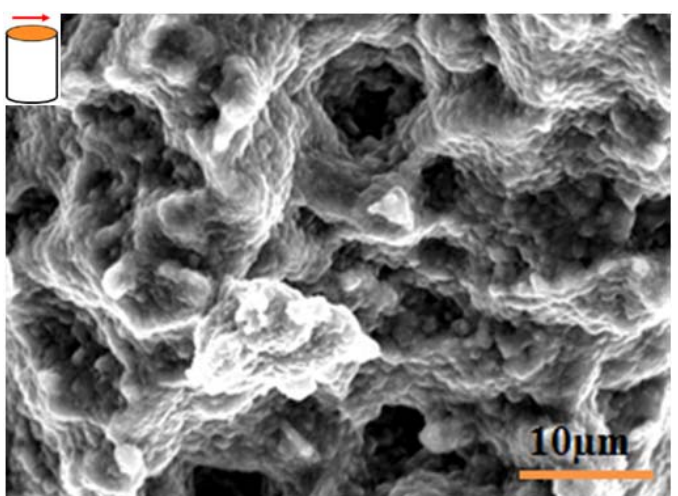

b)

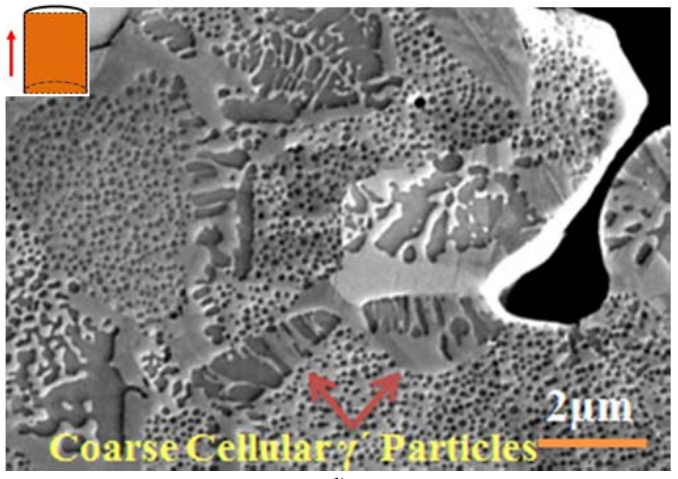

d)

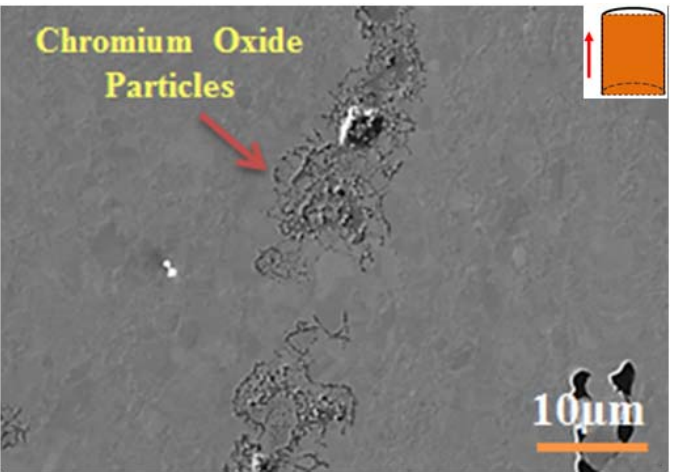

e)

Fig. 10. Transverse and longitudinal fracture surface of samples tested at $850^{\circ} \mathrm{C}$ under $100 \mathrm{MPa}$ stress showing a) necking b) coalescence of voids at the center of the neck c) and d) PFZ formation and lamellar coarsening of $\gamma^{\prime}$ particles, crack and cavity initiation in PFZ e) chromium oxide particles. Transverse and longitudinal directions are shown by brown color. 


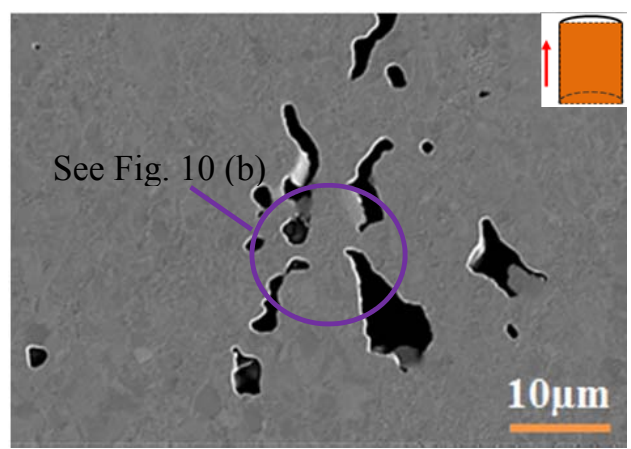

Back scatter electron image

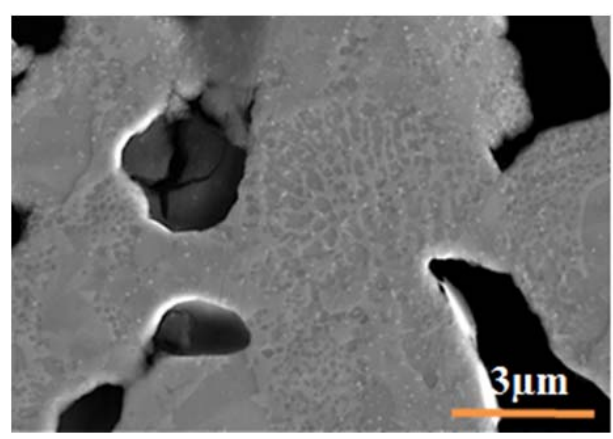

Higher magnification of a)

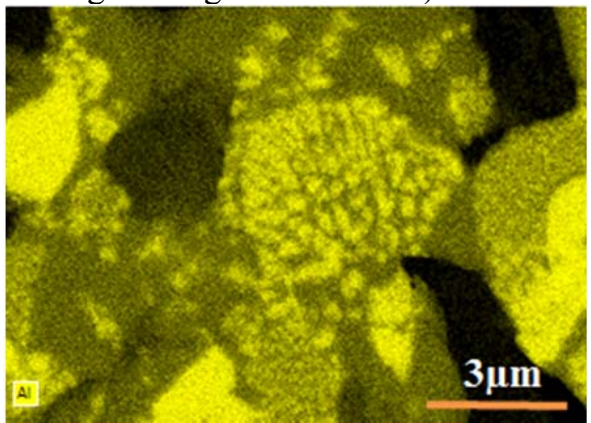

Al-

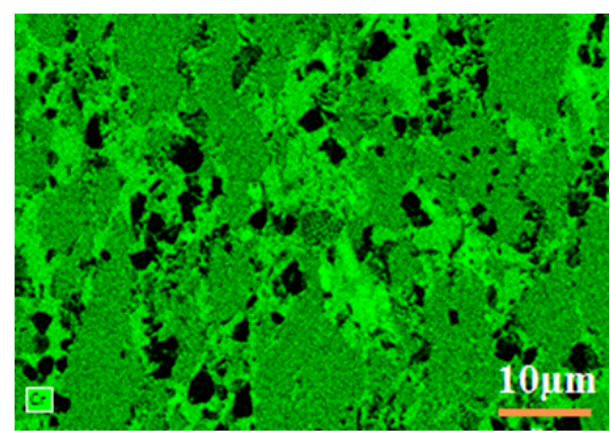

Cr-

a)

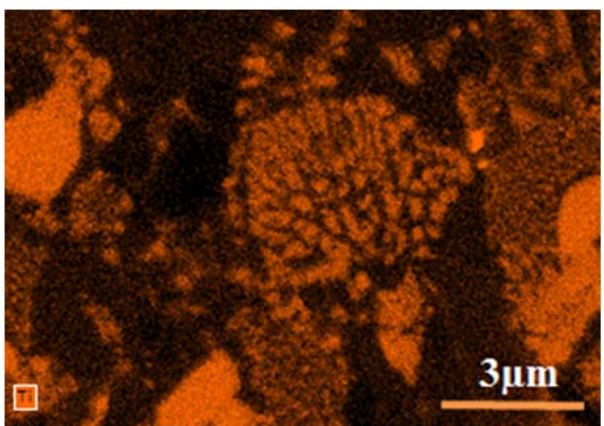

Ti-

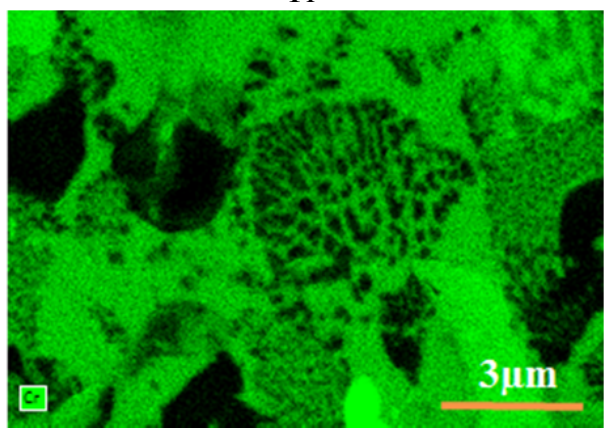

$\mathrm{Cr}-$

b)

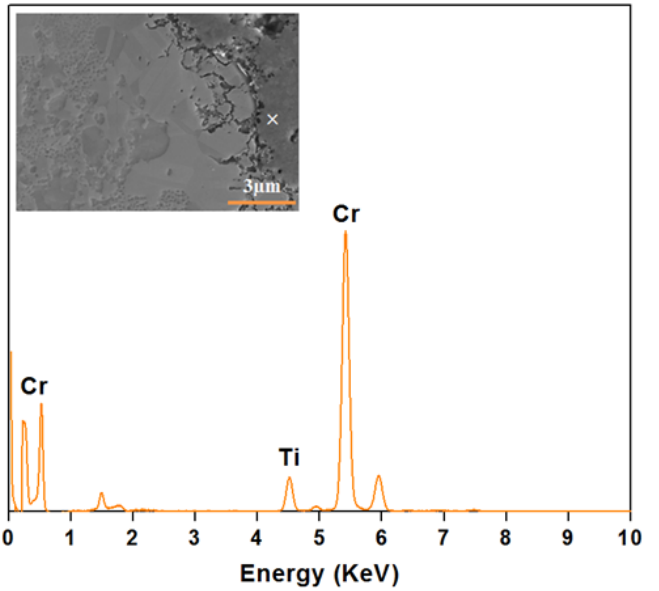

C) Chemical analysis of area adjacent to GB

Fig. 11. EDS mapping results and chemical analysis of the samples tested at $850^{\circ} \mathrm{C} / 100 \mathrm{MPa}$ showing Chromium enrichment at the grain boundary. Longitudinal direction is shown by brown color. 


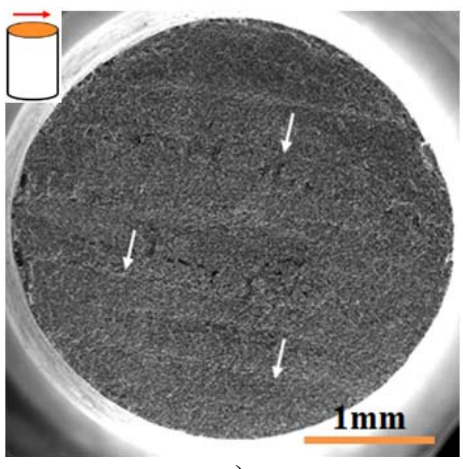

a)

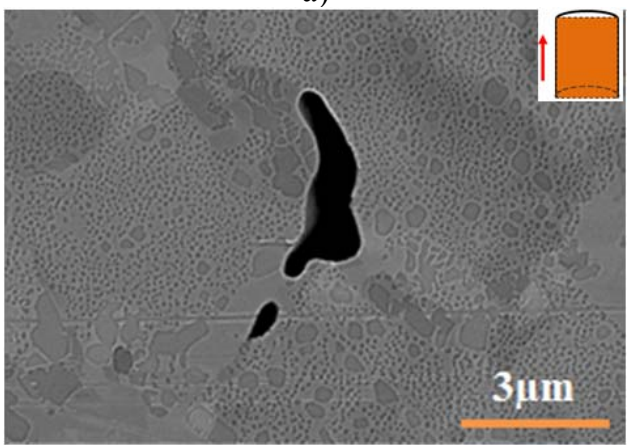

c)

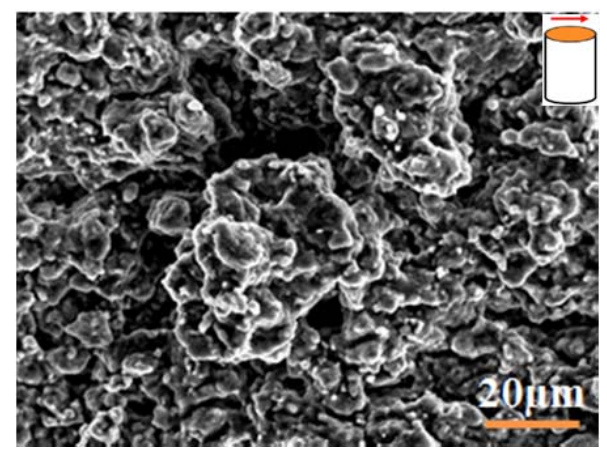

b)

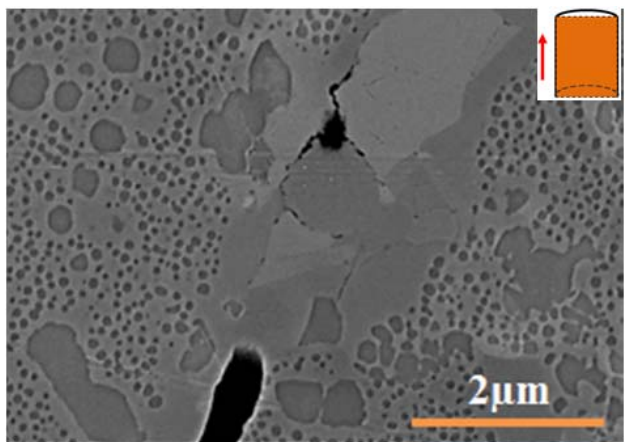

d)

Fig. 12. Transverse and longitudinal observations of post-failure of samples tested in $850^{\circ} \mathrm{C}$ under $200 \mathrm{MPa}$ stress showing a) parallel strips on flat fracture surface, as marked by white arrows b) decohesion of grain due to crack connection c) and d) PFZ and cavity formation adjacent to GB. Transverse and longitudinal directions are shown by brown color.

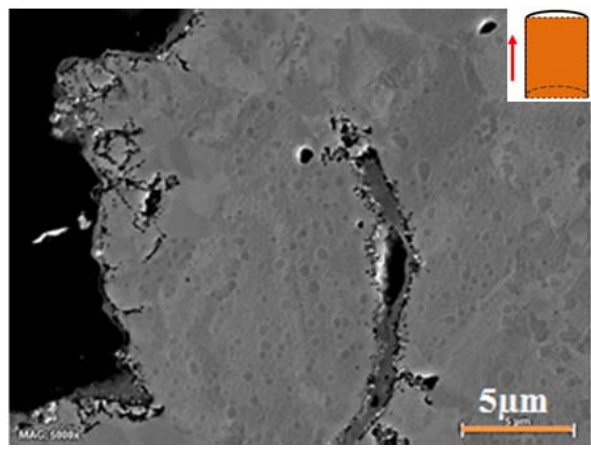

a) Back scatter electron image

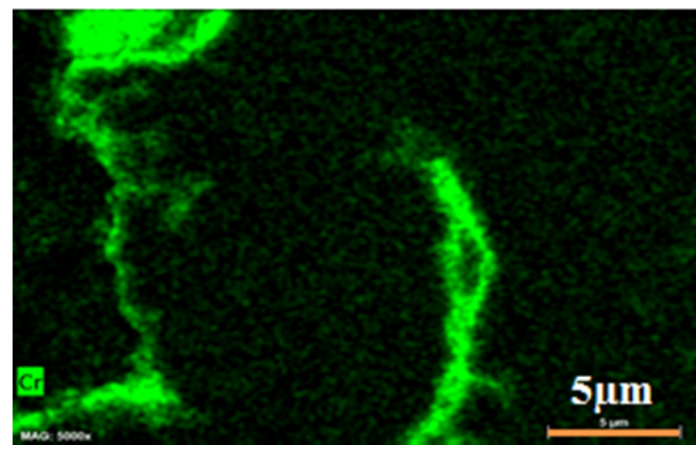

b) $\mathrm{Cr}-$

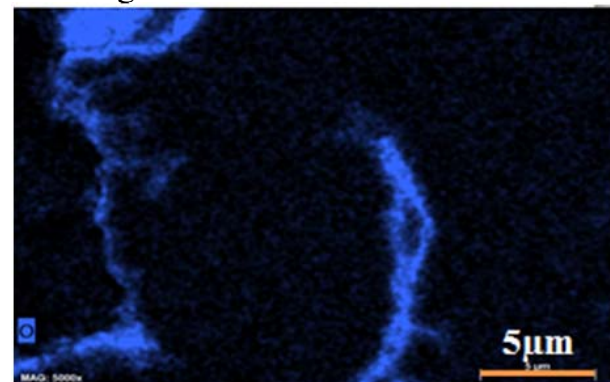

c) $\mathrm{O}-$

Fig. 13. EDS mapping results of the creep tested specimen at $850^{\circ} \mathrm{C} / 200 \mathrm{MPa}$ showing oxide and crack formation at GB. Longitudinal direction is shown by brown color. 